\title{
Operative Versus Nonoperative Management of Nonfunctioning Pancreatic Neuroendocrine Tumors
}

\section{Citation}

Zhang, Irene Y. 2017. Operative Versus Nonoperative Management of Nonfunctioning Pancreatic Neuroendocrine Tumors. Doctoral dissertation, Harvard Medical School.

\section{Permanent link}

http://nrs.harvard.edu/urn-3:HUL.InstRepos:40621372

\section{Terms of Use}

This article was downloaded from Harvard University's DASH repository, and is made available under the terms and conditions applicable to Other Posted Material, as set forth at http:// nrs.harvard.edu/urn-3:HUL.InstRepos:dash.current.terms-of-use\#LAA

\section{Share Your Story}

The Harvard community has made this article openly available.

Please share how this access benefits you. Submit a story.

\section{Accessibility}


Scholarly Report submitted in partial fulfillment of the MD Degree at Harvard Medical School

Date: 1 February 2017

Student Name: Irene Y. Zhang

Scholarly Report Title: Operative Versus Nonoperative Management of Nonfunctioning Pancreatic Neuroendocrine Tumors

Mentor Name(s) and Affiliations: Cristina R. Ferrone, MD, Department of General \& Gastrointestinal Surgery, Massachusetts General Hospital

\section{Collaborators, with Affiliations:}

Jing Zhao, Massachusetts General Hospital

Carlos Fernandez-del Castillo, MD, Massachusetts General Hospital

Yvonne Braun, MD, Massachusetts General Hospital

Shadi Razmdjou, MD, Massachusetts General Hospital

Andrew L. Warshaw, MD, Massachusetts General Hospital

Keith D. Lillemoe, MD, Massachusetts General Hospital 


\section{ABSTRACT}

\section{Operative Versus Nonoperative Management of Nonfunctioning Pancreatic}

Neuroendocrine Tumors.

Irene Y. Zhang, Jing Zhao, Carlos Fernandez-del Castillo, Yvonne Braun, Shadi Razmdjou, Andrew L. Warshaw, Keith D. Lillemoe, Cristina R. Ferrone

Introduction: Surgical resection is the only curative treatment for pancreatic neuroendocrine tumors (PNETs), but pancreatic operations carry a significant morbidity. We investigated whether the resection of small, asymptomatic nonfunctioning PNETs is beneficial. Clinicopathologic factors were retrospectively reviewed for all PNET cases from 1998 to 2014.

Methods: Kaplan-Meier survival and multivariable regression analyses were performed. A total of 249 patients had nonfunctioning PNETs with adequate follow-up, of whom 193 were resected and 56 were observed. Median age was 56 years, and $48 \%$ of the patients were female.

Results: Overall, the resected patients had a significantly longer survival (OS) $(p=0.001)$. However, for the patients with PNETs $\leq 2.5 \mathrm{~cm}$ in size and without metastasis at presentation, tumor size significantly modified the effect of resection on overall survival $(p<0.05)$. The protective effect of resection increased as tumor size increased. An operation became a significant predictor of overall survival for tumors $>1.5 \mathrm{~cm}(\mathrm{p}=0.050$ or less for larger tumors) but was not significant for tumors $<1.5 \mathrm{~cm}(\mathrm{p}=0.317$ or more for smaller tumors), controlling for age-adjusted Charlson comorbidity index.

Conclusion: Resection of nonfunctioning PNETs over $1.5 \mathrm{~cm}$ is independently and significantly associated with a longer survival. However, the benefit of resection for tumors under $1.5 \mathrm{~cm}$ is unclear. 


\section{STUDENT'S CONTRIBUTION}

Under the mentorship of principal investigator Dr. Cristina Ferrone, I initiated this research project in 2014 and helped to develop the research questions and hypotheses. After applying for and receiving IRB approval for the study, I created an institutional database of patients with pancreatic neuroendocrine tumors. I did the primary work for patient identification and data collection through retrospective chart review, with assistance in querying the institution's electronic medical records for relevant patients (by ICD-9 codes) from Yvonne Braun and Shadi Razmdjou. I then collaborated with Jing Zhao in the biostatistics department to conduct the statistical analysis of the data. In discussion with Dr. Ferrone, I helped to design the different parts of our analysis, and Jing completed the statistics, including developing KaplanMeier curves and multivariable regression models. Jing and I worked closely and had regular discussions on how best to structure our analysis and interpret the results. Finally, I synthesized our results with Dr. Ferrone. I wrote the manuscript describing our findings as first author, with guidance and revisions from Dr. Ferrone, as well as Dr. Warshaw, Dr. Fernandez, and Dr. Lillemoe. I also presented the results from this project at two meetings in 2015. 


\section{PUBLICATION INFORMATION}

Zhang IY, Zhao J, Fernandez-del Castillo C, Braun Y, Razmdjou S, Warshaw AL, Lillemoe KD, Ferrone CR. Operative versus nonoperative management of nonfunctioning pancreatic neuroendocrine tumors. Journal of Gastrointestinal Surgery. 2016; 20:277-283.

https://www.ncbi.nlm.nih.gov/pubmed/26691146

http://link.springer.com/article/10.1007\%2Fs11605-015-3043-5 